\title{
Methodologies for high efficiency perovskite solar cells
}

\author{
Nam-Gyu Park
}

\begin{abstract}
Since the report on long-term durable solid-state perovskite solar cell in 2012, perovskite solar cells based on lead halide perovskites having organic cations such as methylammonium $\mathrm{CH}_{3} \mathrm{NH}_{3} \mathrm{Pbl}$ or formamidinium $\mathrm{HC}_{2}\left(\mathrm{NH}_{2}\right)_{2} \mathrm{Pbl}_{3}$ have received great attention because of superb photovoltaic performance with power conversion efficiency exceeding $22 \%$. In this review, emergence of perovskite solar cell is briefly introduced. Since understanding fundamentals of light absorbers is directly related to their photovoltaic performance, opto-electronic properties of organo lead halide perovskites are investigated in order to provide insight into design of higher efficiency perovskite solar cells. Since the conversion efficiency of perovskite solar cell is found to depend significantly on perovskite film quality, methodologies for fabricating high quality perovskite films are particularly emphasized, including various solution-processes and vacuum deposition method.
\end{abstract}

Keywords: Perovskite, Solar cell, Photovoltaics, Lead halide, Organic inorganic hybrid

\section{Introduction}

Organic-inorganic metal halide perovskites with chemical formula $\mathrm{ABX}_{3}\left(\mathrm{~A}=\mathrm{CH}_{3} \mathrm{NH}_{3}, \mathrm{~B}=\mathrm{Pb}\right.$ or $\mathrm{Sn}, \mathrm{X}=\mathrm{I}$, $\mathrm{Br}$ or $\mathrm{Cl}$ ) were discovered in $1978[1,2] . \mathrm{MAPbX}_{3}$ $\left(\mathrm{M}=\mathrm{CH}_{3} \mathrm{NH}_{3}\right)$ changes its color from colorless to orange and to black as anion changes from $\mathrm{Cl}$ to $\mathrm{Br}$ and to I, respectively, due to decrease in band gap energy. Low band gap iodide perovskite is expected to be a potential candidate for solar cell light harvester, however little attention has been paid to such a possibility because of being keen on change in electrical property depending on structural dimensionality reported in 1994 [3]. In 2009, Miyasaka et al. used $\mathrm{MAPbI}_{3}$ and $\mathrm{MAPbBr}_{3}$ as light harvesters for the first time in dye-sensitized solar cell structure, in which $\mathrm{MAPbI}_{3}$ deposited on nanocrystalline $\mathrm{TiO}_{2}$ surface demonstrated a power conversion efficiency (PCE) of $3.8 \%$ [4]. To deposit $\mathrm{MAPbI}_{3}$ on $\mathrm{TiO}_{2}$, MAI and $\mathrm{PbI}_{2}$ were dissolved in gamma-butyrolactone (GBL) and the solution was spin-coated, where Miyasaka group prepared $8 \mathrm{wt} \%$ coating solution. It was found that the $8 \mathrm{wt} \%$ concentration was too low to induce sufficient coverage

*Correspondence: npark@skku.edu

School of Chemical Engineering and Department of Energy Science,

Sungkyunkwan University (SKKU), Suwon 440-746, Republic of Korea of $\mathrm{TiO}_{2}$ surface with $\mathrm{MAPbI}_{3}$. In 2011, Park et al. solved this problem by modulating coating solution concentration from 10 to $40 \mathrm{wt} \%$ and found that $40 \mathrm{wt} \%$ solution was enough to cover the $\mathrm{TiO}_{2}$ surface, leading dark color even at 3-4 $\mu \mathrm{m}$ thick $\mathrm{TiO}_{2}$ film and a PCE of $6.5 \%$ [5]. Absorption coefficient of $\mathrm{MAPbI}_{3}$ deposited on $\mathrm{TiO}_{2}$ film was found to be one order of magnitude higher than the ruthenium-based organometallic dye coded as N719 adsorbed on the same thick $\mathrm{TiO}_{2}$ film. Although these two initial works on perovskite solar cells $[4,5]$ attracted attention, relatively low PCE values and chemical instability of organic-inorganic hybrid perovskite in polar liquid electrolyte due to ionic characteristics were serious obstacle toward further progress of perovskite solar cell.

In 2012, Park et al. demonstrated a long-term durable high efficiency perovskite solar cell for the first time by replacing a liquid electrolytes with a solid hole-transporting material (HTM), which showed a PCE of $9.7 \%$ at submicron thick $\mathrm{TiO}_{2}$ film covered with $2 \mathrm{~nm}$-sized nano dot $\mathrm{MAPbI}_{3}$ [6]. This solid-state perovskite solar cell confirmed $500 \mathrm{~h}$ stability even without encapsulation because nano dot $\mathrm{MAPI}_{3}$ was fully wrapped with hydrophobic spiro-MeOTAD HTM. Two month later, Snaith et al. reported solid-state perovskite solar cell with the same HTM but different oxide $\mathrm{Al}_{2} \mathrm{O}_{3}$, which demonstrated a 
PCE of $10.9 \%$ [7]. Contrary to the $\mathrm{MAPbI}_{3}-\mathrm{TiO}_{2}$ combination, electron injection is not expected from $\mathrm{MAPbI}_{3}$ to $\mathrm{Al}_{2} \mathrm{O}_{3}$ since the condition band position of $\mathrm{Al}_{2} \mathrm{O}_{3}$ is higher than that of $\mathrm{MAPbI}_{3}$. This implies that perovskite acts differently from the organic dye molecules requiring electron injection process.

Reports on solid-state perovskite solar cell with high efficiency and stability have been followed by a surge of interest in perovskite solar cell. Based on Web of Science data (http://ipscience.thomsonreuters.com/product/webof-science/), around 1300 peer-reviewed research papers on perovskite solar cells were published in 2015 (see Fig. 1), which is almost three time higher than the publications in the previous year. The monthly rate of publication is about 110 /month in 2015 , which is expected to increase since research papers as many as 250 are already published only within 2 months, as of February 29, 2016. Thanks to the pioneering works on solid-state perovskite solar cell in 2012 [6, 7], a PCE of $22.1 \%$ was achieved in 2016 from the certification institute NREL (www.nrel. gov).

\section{Review}

\subsection{Optio-electronic properties of organic lead halide perovskite}

Opto-electronic properties of halide perovskites are primarily important in photovoltaics. Absorption coefficient of $\mathrm{MAPbI}_{3}$ was first estimated to be $1.5 \times 10^{4}$ $\mathrm{cm}^{-1}$ at $550 \mathrm{~nm}$ in the form of nanodots deposited in the mesoporous $\mathrm{TiO}_{2}$ film [5]. Room temperature absorption coefficients of $\mathrm{MAPbI}_{3}$ and $\mathrm{MAPbI}_{3}: \mathrm{Cl}$ films were evaluated by several groups using UV-Vis absorbance data combining with the effect of reflection, spectroscopic ellipsometry considering polarized reflection and photothermal deflection spectroscopy [8-17], which was summarized by Green et al. [18]. All the measured data

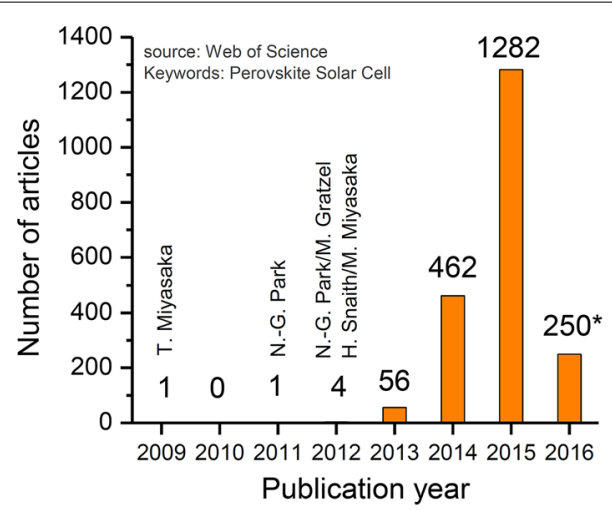

Fig. 1 Publications on perovskite solar cells. Data are collected based on Web of Science using keywords "perovskite solar cell" showed that absorption coefficients range from $2.5 \times 10^{4}$ to $8.9 \times 10^{4} \mathrm{~cm}^{-1}$ at $620 \mathrm{~nm}$. Among the methods for determining absorption coefficient, ellipsometry may be inaccurate at around band gap transition because high absorption coefficients were shown even below the band edge.

The refractive index is related to how much the speed of light is reduced through a material, compared to the vacuum speed, and the dielectric constant tells us how much the electric field is attenuated in a substance, compared to vacuum. Since light is an electromagnetic wave, two parameters are basically connected each other. Refractive index and dielectric constant for $\mathrm{MAPbI}_{3}$ were reported by several groups $[8,10-15]$, where the real $(n)$ and imaginary $(k)$ parts of the refractive index are related to those of dielectric constants with the real part $\left(\varepsilon_{1}=n^{2}-k^{2}\right)$ and imaginary part $\left(\varepsilon_{2}=2 n k\right)$. Imaginary part of refractive index is related to the strength of absorption loss at a particular wavelength (extinction coefficient). Figure 2 shows the real and imaginary parts of refractive index and dielectric constant [18]. A large deviation in the real part of refractive index stems from different layer thickness, morphology, chemical composition, and material anisotropy etc. of the $\mathrm{MAPbI}_{3}$ films. The real part of refractive index of $\mathrm{MAPbI}_{3}$ ranges between 2.3 and 2.6. Theoretical estimation based on direct band gap energy [19] leads to the refractive index of 2.5 for the bang gap of $1.6 \mathrm{eV}$ of $\mathrm{MAPbI}_{3}$, which is well consistent with the measured value. The infrared refractive index of the $\mathrm{ABX}_{3}$ halide perovskites can be simply estimated using band gap energy $\left(E_{g}\right)$ via the simple relationship, $n^{2} \approx 1+8.32 \mathrm{eV} / \mathrm{E}_{\mathrm{g}}[18,19]$. The infrared refractive index of $\mathrm{MAPbI}_{3}(\mathrm{n}=2.5)$ is lower than that of GaAs $(\mathrm{n}=3.3)$ [20].

Since dielectric constant determines the magnitude of the coulomb interaction between electron-hole pairs and charge carriers as well as any fixed ionic charges in the lattice, high dielectric constants are required for high efficiency solar cell. Usually inorganic materials have higher dielectric constants than organic materials. Dielectric constant for $\mathrm{MAPbI}_{3}$ is in the range of 5-7 as can be seen in Fig. 2. Higher value for the relative dielectric constant of $\mathrm{MAPbI}_{3}$ was estimated to be about 18 from capacitive measurement [21]. Low effective mass is also required for high efficiency solar cell since effective mass decreases as the carrier becomes more delocalized and its transport becomes more wavelike. Effective mass of electron and hole can be estimated by band structure.

$\mathrm{MAPbI}_{3}$ was reported to be a direct bandgap material, where the conduction band minimum (CBM) is aligned with the top of the valence band maximum (VBM) at the same effective momentum $(k=0)$. When the alignment of bandedges in the VBM and the CBM occurs at 

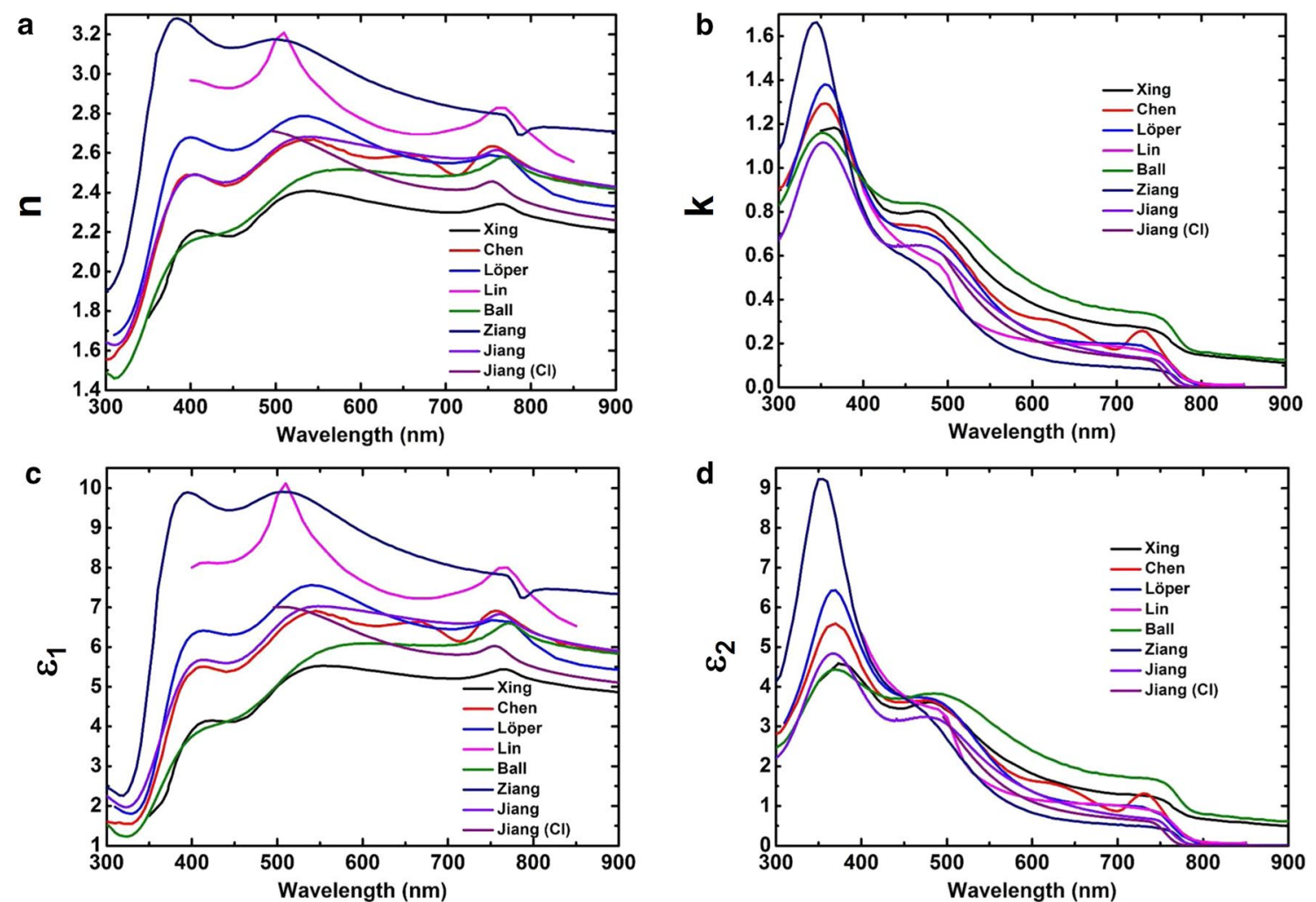

Fig. 2 a Real $(n)$ and $\mathbf{b}$ imaginary $(k)$ part of refractive index and $\mathbf{c}$ real $\left(\varepsilon_{1}\right)$ and $\mathbf{d}$ imaginary $\left(\varepsilon_{2}\right)$ part of dielectric constant of room temperature $\mathrm{MAPbl}_{3}$. Reprinted with permission from Ref. [18]

$\mathrm{k}=0$, the band structures can be simply obtained using the relation $\mathrm{E}(\mathrm{k})=\hbar^{2} \mathrm{k}^{2} / 2 \mathrm{~m}^{*}[22]$, where $\hbar(=\mathrm{h} / 2 \pi), \mathrm{k}$ and $\mathrm{m}^{*}$ represent Planck's constant, effective momentum and effective mass, respectively. Figure 3 displays the band structure and the first Brillouin zones (BZ) for the 3 dimensional cubic $\mathrm{MAPbI}_{3}$ [23]. Direct bandgap of $\mathrm{MAPbI}_{3}$ is located at the high symmetry point R. In $\mathrm{E}-\mathrm{k}$ diagram, effective mass can be obtained from second derivatives of $\mathrm{E}(\mathrm{k})$ with respect to $\mathrm{k}$, leading to $\left(1 / \hbar^{2}\right) \mathrm{dE}^{2} / \mathrm{d}^{2} \mathrm{k}=2 \mathrm{C}_{1} / \hbar^{2}=1 / \mathrm{m}_{\mathrm{e}}$ " for electron and $-2 \mathrm{C}_{2} /$ $\hbar^{2}=1 / \mathrm{m}_{\mathrm{h}}{ }^{*}$ for hole [22]. This indicates that the constants $\mathrm{C}_{1}$ and $\mathrm{C}_{2}$ in the approximated parabolic curves of CBM for electron and VBM for hole are inversely proportional to effective mass, respectively. As shown in Fig. 3, effective masses of electron and hole are expected to be similar because of similar E-k parabolic feature. In $\mathrm{MAPbI}_{3}$ the effective mass of electron and hole was estimated to be 0.23 and 0.29 , respectively [24]. The comparable effective mass between electron and hole implies kinetically similar ambipolar characteristics of $\mathrm{MAPbI}_{3}$. Although transport of electron and hole is balanced, electron diffusion length $(\sim 130 \mathrm{~nm})$ is 1.4 times longer than hole diffusion length $(\sim 90 \mathrm{~nm})$ for the solution-processed $\mathrm{MAPbI}_{3}$ [25], while hole diffusion length $(\sim 800 \mathrm{~nm})$ is 4.6 times longer than electron diffusion length $(\sim 180 \mathrm{~nm})$ for $\mathrm{FAPbI}_{3}[26]$. Hall measurement revealed that $\mathrm{MAPbI}_{3}$ is close to n-type property but $\mathrm{FAPbI}_{3}$ has p-type character [27]. Carrier effective masses along with opto-electronic parameters such as exciton binding energy and dielectric constants are displayed in Table 1 for $\mathrm{APbI}_{3}$ perovskites ( $\mathrm{A}=\mathrm{MA}$ and FA) based on a simple two band k.p perturbation theory [28].

Charge-carrier mobility plays important role in charge extraction to electrode. Charge-carrier mobility of $\mathrm{FAPbI}_{3}$ was estimated to be about $27 \mathrm{~cm}^{2} / \mathrm{Vs}$ as measured by $\mathrm{THz}$ photoconductivity transient [29] that is similar to the solution-process $\mathrm{MAPbI}_{3}$ [30]. For the mixed-halide perovskite with fromamidinium cation, charge-carrier mobility was found to decrease as bromide content increases from $\mathrm{y}=0$ to $\mathrm{y}=0.5$ in $\mathrm{FAPb}\left(\mathrm{Br}_{\mathrm{y}} \mathrm{I}_{1-\mathrm{y}}\right)_{3}$, significant drop to about $2 \mathrm{~cm}^{2} / \mathrm{Vs}$ at $0.3<\mathrm{y}<0.5$, but recover the mobility up to 14 for the tri-bromide of $y=1$ [29], where very low carrier mobility found at $0.3<y<0.5$ was related to amorphous phase.

Internal PL quantum yield (iQY) is important because it affects directly open-circuit voltage $\left(\mathrm{V}_{\text {oc }}\right)$ and photovoltaic performance. The optically implied $V_{o c}$, reflecting the maximum $\mathrm{V}_{\mathrm{oc}}$ that can be achieved purely based on 

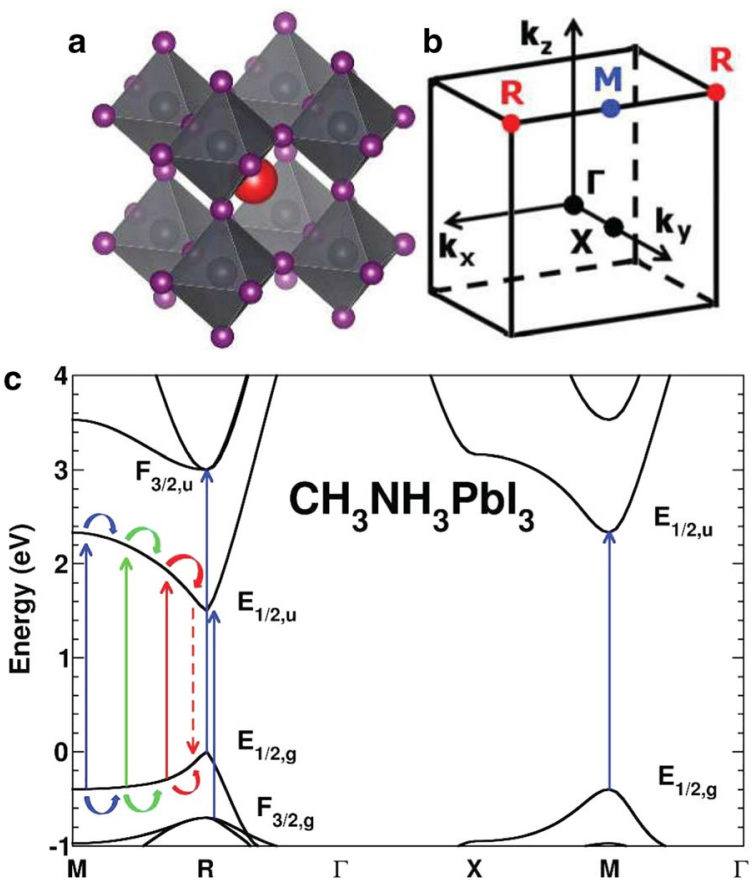

Fig. 3 a Real-space $3 D$ view of the cubic crystal structure of $\mathrm{AMX}_{3}$ $\left(\mathrm{A}=\mathrm{Cs}, \mathrm{CH}_{3} \mathrm{NH}_{3}, \mathrm{M}=\mathrm{Pb}, \mathrm{Sn}\right.$, and $\mathrm{X}=\mathrm{I}, \mathrm{Br}, \mathrm{Cl}$ ) with the Pm3m space group. $\mathrm{CH}_{3} \mathrm{NH}_{3}{ }^{+}$cation (red ball) is located at the center of the cube. b Reciprocal-space 3D view showing the first BZ of the Pm3m space group. Points of high symmetry in the cubic $B Z$ : $\lceil$ denotes the origin of the $B Z ; X$ is the center of a square face at the $B Z$ boundary; $M$ is a center of a cube edge; and Rs are vertices of the cube. $\mathbf{c}$ Electronic band structure for the high-temperature cubic $\mathrm{Pm} 3 \mathrm{~m}$ phase of $\mathrm{MAPbl}_{3}$ with spin-orbit coupling (SOC) at the local density approximation (LDA) level of theory. An upward energy shift of $1.4 \mathrm{eV}$ has been applied to match the experimental bandgap value at R. Irreducible representations obtained from a Pm3m double group analysis are given at $\mathrm{R}$ and $\mathrm{M}$ points for the electronic states close to the band gap. Vertical arrows show various possible optical transitions close to the band gap energy. Optical transitions along the line between the $M$ and $R$ points generate carriers that easily relax toward the $R$ point. Reprinted with permission from 23

the intrinsic material quality, assuming no optical losses nor losses caused by nonideal contact architectures, is defined as $q \mathrm{~V}_{\text {oc }}=\mathrm{E}_{\mathrm{g}}-\mathrm{T} \Delta \mathrm{S}-\mathrm{kT}|\ln \mathrm{iQY}|$ [31], where $q$ is the elementary charge, $\mathrm{E}_{\mathrm{g}}$ is the band gap, $\mathrm{k}$ is the Boltzmann constant, $\mathrm{T}$ is the absolute temperature, and $\mathrm{S}$ is the entropy. The optically implied $\mathrm{V}_{\text {oc }}$ was evaluated for $\mathrm{MAPbI}_{3-\mathrm{x}} \mathrm{Br}_{\mathrm{x}}$ based on the illumination-intensitydependent maximum iQY of $30 \%$ for $0.1<\mathrm{x}<1.4$ and the entropy of $260 \mathrm{meV}$ in the band gap range of 1.0$1.8 \mathrm{eV}$. The $\mathrm{V}_{\text {oc }}$ deficit $\left(\mathrm{E}_{\mathrm{g}} / q-\mathrm{V}_{\mathrm{oc}}\right)$ was estimated to be about $400 \mathrm{mV}$ at 1 sun up to a band gap of $1.97 \mathrm{eV}$, which means, for instance, electrical $\mathrm{V}_{\text {oc }}$ of about $1.2 \mathrm{~V}$ can be expected for the band gap of $1.6 \mathrm{eV}$. The $\mathrm{V}_{\text {oc }}$ deficit will be further reduced by about $60 \mathrm{mV}$ at optimized carrier injection level [31].
Table 1 Bandgap $\left(E_{g}\right)$, exciton binding energy $\left(R^{*}\right)$, reduced effective mass $(\mu)$, effective dielectric constant $\left(\varepsilon_{\text {eff }}\right)$ for $\mathrm{MAPbl}_{3}$ and $\mathrm{FAPbl}_{3}$

\begin{tabular}{lllllr}
\hline Compound & $\boldsymbol{E}_{\mathbf{g}}(\mathbf{m e V})$ & $\boldsymbol{R}^{*}(\mathbf{m e V})$ & $\boldsymbol{\mu}\left(\mathbf{m}_{\mathbf{e}}\right)$ & $\boldsymbol{\varepsilon}_{\text {eff }}$ & Temperature \\
\hline $\mathrm{FAPbl}_{3}$ & 1521 & 10 & 0.095 & 11.4 & $140-160$ \\
$\mathrm{MAPbl}_{3-x} \mathrm{Cl} \mathrm{I}_{x}$ & 1600 & 10 & 0.105 & 11.9 & $190-200$ \\
$\mathrm{MAPb}_{3}$ & 1608 & 12 & 0.104 & 10.9 & $155-190$ \\
$\mathrm{FAPbBr}_{3}$ & 2294 & 24 & 0.13 & 8.6 & $160-170$ \\
\hline
\end{tabular}

Reprinted with permission from Ref. [28]

\subsection{Methodologies for fabricating high efficiency perovskite solar cells \\ 2.2.1 Solution-processed two-step method}

Two-step sequential deposition was first proposed by Mitzi et al. [32], where $\mathrm{PbI}_{2}$ was deposited on substrate prior to MAI treatment by either vacuum evaporation or spinning coating. The $\mathrm{PbI}_{2}$ coated substrate was dipped in MAI solution. Saturated methanol solution of $\mathrm{PbI}_{2}$ was used as precursor solution for spin-coating process. The $\mathrm{PbI}_{2}$ thin film was immersed in the 2-rpopanol solution containing MAI, which was followed by rinsing with 2-propanol. Dipping time will be crucial to the final product. This two-step method was applied to perovskite solar cell by Gratzel group [33]. Similar procedure was performed, where $\mathrm{PbI}_{2}$ layer was formed on the mesoporous $\mathrm{TiO}_{2}$ film (average particle size of $\mathrm{TiO}_{2}$ was about $20 \mathrm{~nm}$ ) by spin coating a $\mathrm{PbI}_{2}$ solution in $N, N$-dimethylformamide (DMF) at $70{ }^{\circ} \mathrm{C}$. The dried $\mathrm{PbI}_{2}$ film was dipped in a solution of MAI in 2-propanol for $20 \mathrm{~s}$. It was described that the best efficiency device was obtained from a slight modified method of prewetting of the $\mathrm{PbI}_{2}$ film by dipping in 2-propanol for one second prior to being dipped in the MAI solution. A certified PCE of $14.1 \%$ was achieved using the two-step method. As mentioned previously, dipping process, such as dipping time and solution concentration, is crucial to the morphology and opto-electronic property of the final $\mathrm{MAPbI}_{3}$ film, associated with the device performance. Two-step spin-coating technology was then proposed to solve the problem occurred by dipping process.

A 2-propanol solution of MAI was spin-coated on the $\mathrm{PbI}_{2}$ film, instead of dipping the $\mathrm{PbI}_{2}$ film in the MAI solution, which was found to create nanocubic perovskite morphology and its size was significantly dependent on the concentration of MAI solution [34]. In Fig. 4 the twostep spin-coating procedure is depicted, where perovskite crystal size and photovoltaic performance were found to be significantly influenced by the MAI concentration. For instance, low concentration produced large cuboid crystal but high concentration yielded small cuboid $\mathrm{MAPbI}_{3}$. Time-dependent crystal growth study revealed that small seed crystals were sparsely grown on the 


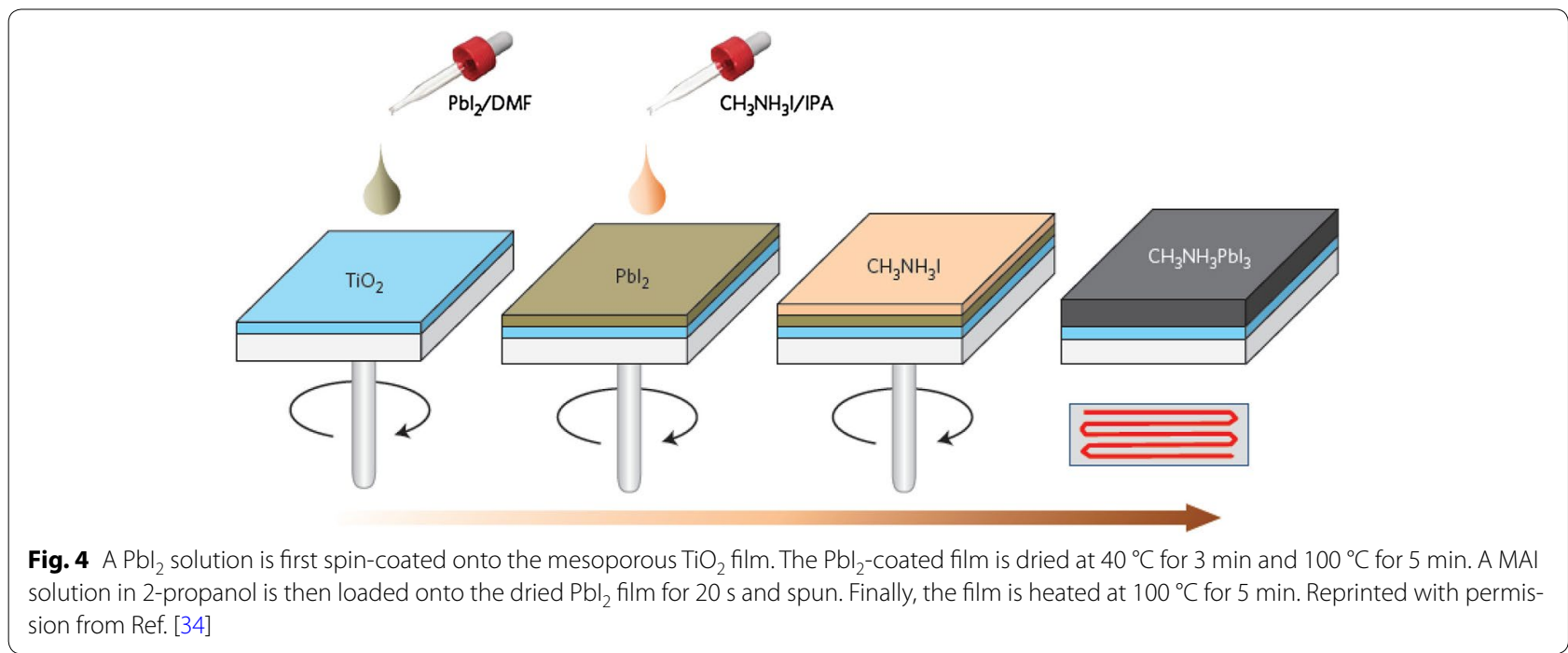

substrate initially for the low MAI concentration, which grew further with time, whereas small seed crystals were fully occupied on the substrate in early stage for the high MAI concentration, inhibiting further growth, as can be seen in Fig. 5. Crystal growth mechanism was explained by thermodynamic Gibbs free energy change [35]. The cuboid size was found to be correlated with concentration of MAI and temperature, where the observed cuboid size depending on the MAI concentration was well fit with the proposed equation [35].

The small cuboids obtained by high MAI concentration were closely packed on the substrate, but the large
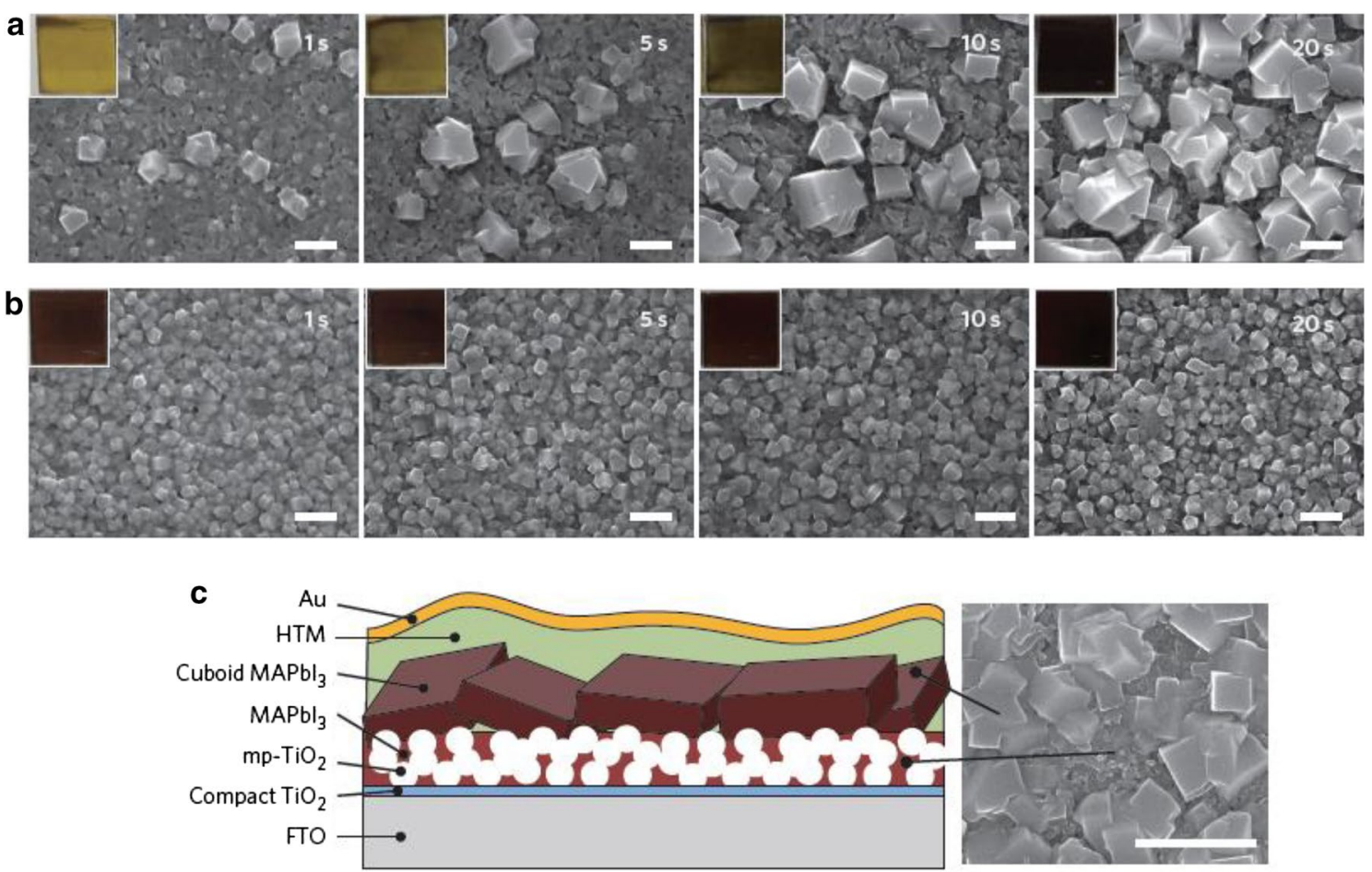

Fig. 5 Surface scanning electron microscopy (SEM) images at different loading times for $\mathbf{a}$ the low concentration of $0.038 \mathrm{M}$ and $\mathbf{b}$ the high concentration of $0.063 \mathrm{M}$ MAI solutions. Insets show photographs of the samples used for SEM measurement. Scale bars $500 \mathrm{~nm}$. c Schematic of the perovskite solar cell configuration based on surface and cross-sectional SEM images, where large cuboid $\mathrm{MAPbl}_{3}$ was formed on top of the mesoporous $\mathrm{TiO}_{2}$ layer. Scale bar (SEM image), $1 \mu \mathrm{m}$. Reprinted with permission from Ref. [34] 
cuboids produced gaps between the cuboids. Thus, large cuboid film exhibited better light harvesting efficiency due to enhanced internal light scattering, leading to higher photocurrent density $\left(\mathrm{J}_{\mathrm{sc}}\right)$. However, largest cuboid $(\sim 800 \mathrm{~nm})$ did not show highest open-circuit voltage $\left(\mathrm{V}_{\text {oc }}\right)$ among the studied sizes ranging from $\sim 90$ to $\sim 800 \mathrm{~nm}$. Instead, medium size of about $200 \mathrm{~nm}$ showed highest $\mathrm{V}_{\mathrm{oc}}$. According to the photo-CELIV (charge extraction by linear increasing voltage) study, fast charge mobility along with high charge extraction ability was observed for the medium sized $\mathrm{MAPbI}_{3}$ cuboid compared to larger or smaller sized ones. Retarding charge mobility may increase the chance of recombination, being responsible for lowering $\mathrm{V}_{\mathrm{oc}}$ for the largest size. This indicates that the mobility for charge extraction plays important role in managing $\mathrm{V}_{\mathrm{oc}}$. Since $\mathrm{J}_{\mathrm{sc}}$ was observed to increase with increasing the $\mathrm{MAPbI}_{3}$ size, one can expect higher $\mathrm{J}_{\mathrm{sc}}$ from the larger size. However, higher $\mathrm{J}_{\mathrm{sc}}$ could not be obtained from the a few micron sized $\mathrm{MAPbI}_{3}$ grown by further decreasing the MAI concentration such as $0.032 \mathrm{M}$. $\mathrm{J}_{\mathrm{sc}}\left(12.8 \mathrm{~mA} / \mathrm{cm}^{2}\right)$ for the $\mathrm{MAPbI}_{3}$ film prepared from $0.032 \mathrm{M}$ was only $56 \%$ of that $\left(22.8 \mathrm{~mA} / \mathrm{cm}^{2}\right)$ for the one prepared from $0.044 \mathrm{M}$ MAI solution [36]. Micro photoluminescence $(\mu-\mathrm{PL})$ studies revealed that the $0.032 \mathrm{M}$ cell had a substantially lower radiative recombination than the $0.044 \mathrm{M}$ one, which eventually led to much lower charge collection efficiency. High resolution $\mu$-PL mapping was investigated to compare the PL intensity and spectral position of the PL peak. In Fig. 6, a strong inhomogeneity in both intensity and spectral position of the peak is observed for the perovskite film prepared with the $0.032 \mathrm{M}$ MAI solution, in which largest crystals show the lowest PL intensity along with red-shift of the PL peak associated with reduced bandgap energy. Such a low PL intensity stems from non-radiative recombination that could be related to crystallinity, grain boundary, trap states and surface defects of perovskite film. Therefore, overall performance of perovskite solar cell is strongly influenced by the electrical and radiative properties of perovskite film.

Two-step deposition technique was found to be beneficial to fabrication of perovskite film at relatively high humidity condition. The substrate pre-heating process for $\mathrm{PbI}_{2}$ deposition in the two-step spin-coating procedure was found to be crucial to the final $\mathrm{MAPbI}_{3}$ morphology and photovoltaic performance, where infiltration of $\mathrm{PbI}_{2}$ in the mesoporous $\mathrm{TiO}_{2}$ film was better for the heated substrate than for the substrate without heating [37]. PCE increased with increasing the substrate temperature from room temperature to $50^{\circ} \mathrm{C}$ and then decreased upon further increasing temperature to $60^{\circ} \mathrm{C}$, exhibiting optimal substrate temperature of around $50{ }^{\circ} \mathrm{C}$. The pre-heating method was found to be not suitable for one-step coating under high relative humidity environment. Humidity effect in fabrication process was examined, where the relative humidity less than $60 \%$ was hard to affect the overall performance [38].

Modified two-step deposition methods were proposed. Vapor treatment of organic solvents such as toluene or chlorobenzene on the $\mathrm{PbI}_{2}$ films resulted in better photovoltaic performance because the increased grains size and surface area of the $\mathrm{PbI}_{2}$ layer provided better reaction sites for MAI [39]. Interdiffusion method was proposed to fabricate $\mathrm{MAPbI}_{3}$ without thermal annealing, where a $\mathrm{MAPbI}_{3}$ film formed from the $\mathrm{MAI} / \mathrm{PbI}_{2}$ bilayer film in air exposure for $30 \mathrm{~min}$ at relative humidity of about $30 \%$ demonstrated a comparable performance to the thermally annealed perovskite [40]. In the two-step process, instead of depositing $\mathrm{PbI}_{2}$ layer, $\mathrm{PbO}$ film was electrochemically deposited on a conductive substrate before reaction with MAI at $150{ }^{\circ} \mathrm{C}$ for $30 \mathrm{~min}$. [41]. A possible reaction mechanism was proposed as follows. The MAI is decomposed to $\mathrm{CH}_{3} \mathrm{NH}_{2}$ and $\mathrm{HI}$ at the elevated temperature at the initial stage, and the generated $\mathrm{HI}$ is reacted with the $\mathrm{PbO}$ to form $\mathrm{PbI}_{2}$. Finally the $\mathrm{PbI}_{2}$ is reacted with MAI to form $\mathrm{MAPbI}_{3}$. The equivalent amount of $\mathrm{H}_{2} \mathrm{O}$ generated during the conversion process from $\mathrm{PbO}$ to $\mathrm{PbI}_{2}$ was argued to have positive effect on the formation of the provskite layer. To prevent volume change in two-step sequential deposition method, a intermediate $\mathrm{PbI}_{2}(\mathrm{DMSO})_{\mathrm{x}}$ was pre-deposited before treatment of organic ammonium halides, which led to a PCE more than $20 \%$ [42].

\subsubsection{Solution-processed single precursor and anti-solvent method}

One-step method seems to be better in terms of minimizing the processing step. However, photovoltaic performance of device made by a simple one-step method is inferior to two-step results because of significant difference in morphology of the $\mathrm{MAPbI}_{3}$ [43]. Thus morphology control is crucial to one-step method. Anti-solvent engineering was proposed to control the crystal growth kinetics [44]. The precursor of MAI and $\mathrm{PbI}_{2}$ was dissolved the mixed solution of $N, N$-dimethylsulfoxide (DMSO) and GBL, which was spin-coated on the substrate. Anti-solvent such as toluene was dripped while spinning the precursor solution, which led to homogeneous and flat perovskite film with well-developed large grains. Figure 7 illustrates a schematic procedure of anti-solvent treatment for one-step deposition method, along with the morphology of $\mathrm{MAPbI}_{3}$ produced by this method. By utilizing the solvent engineering technique, high PCE of $18.4 \%$ was achieved from the solid solution between $\mathrm{FAPbI}_{3}$ and $\mathrm{MAPbBr}_{3}$ with ratio of $85 \%: 15 \%$ [45]. 

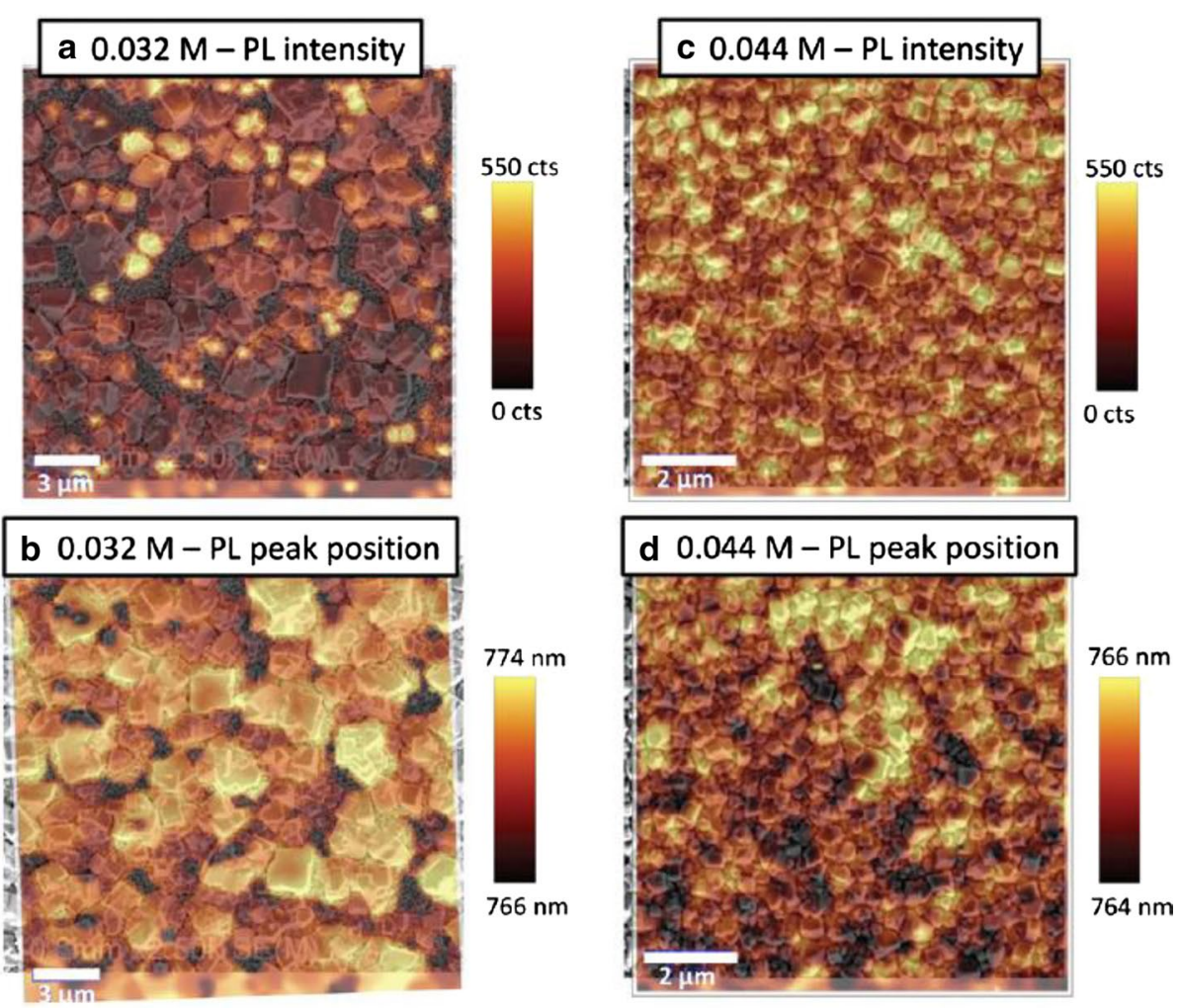

Fig. 6 a, $\mathbf{c} \mu$-PL intensity and $\mathbf{b}$, d spectral position of the $\mathrm{PL}$ peak for the layout of TCO/bl- $\mathrm{TiO}_{2} / \mathrm{mp}-\mathrm{TiO}_{2} / \mathrm{MAPbl}_{3}$ with $0.032 \mathrm{M}$ and $0.044 \mathrm{M} \mathrm{MAl}$ concentration. High resolution $\mu$-PL imaging overlaid with SEM images acquired on the same spot. Note the different color bars in $\mathbf{b}, \mathbf{d}$ which is $766-774 \mathrm{~nm}$ for the $0.032 \mathrm{M}$ sample and has a much smaller range $(764-766 \mathrm{~nm}$ ) for the $0.044 \mathrm{M}$ sample. The scale bar is $3 \mu \mathrm{m}$ for the $0.032 \mathrm{M}$ film and $2 \mu \mathrm{m}$ for $0.044 \mathrm{M}$. Reprinted with permission from Ref. [36]

Fast deposition-crystallization (FDC) procedure was proposed to produce uniform and flat $\mathrm{MAPbI}_{3}$ film [46] to overcome non-uniform $\mathrm{MAPbI}_{3}$ film with pinholes that is usually produced by one-step deposition of a DMF solution containing MAI and $\mathrm{PbI}_{2}$ because of slow crystallization due to high boiling point of DMF $\left(153^{\circ} \mathrm{C}\right)$. Detailed $\mathrm{FDC}$ method is as follows. A DMF solution of $\mathrm{MAPbI}_{3}$ was first spin-coated on the $\mathrm{bl}-\mathrm{TiO}_{2}$ layer. After a specific delay time, a second solvent (anti-solvent) was quickly added to the substrate, where the use of the second solvent is to promote fast nucleation and growth of $\mathrm{MAPbI}_{3}$ by reducing the solubility of $\mathrm{MAPbI}_{3}$ in the mixed solvent. 12 solvents were tested, including chlorobenzene, benzene, xylene, toluene, methanol, ethanol, ethylene glycol, 2-propanol, chloroform, THF, acetonitrile, and benzonitrile. Figure 8 shows the schematic procedure of FDC using anti-solvent of chlorobenzene and the difference in morphology of $\mathrm{MAPbI}_{3}$ between with and without anti-solvent, where large grain approaching micron scale and highly crystalline nature are clearly shown for the perovskite prepared by FDC method.

\subsubsection{Solution-processed adduct method}

As one of effective methods, Lewis acid-base adduct approach was proposed to prepare high quality of $\mathrm{MAPbI}_{3}$ perovskite film [47]. The interaction between DMSO as a Lewis base and $\mathrm{PbI}_{2}$ as a Lewis acid led to a transparent adduct film which was converted to $\mathrm{MAPbI}_{3}$ by removing DMSO at mild heat treatment. In Fig. 9, a schematic procedure of the adduct approach is presented. The equimolar mixture of $\mathrm{PbI}_{2}$, MAI and DMSO in DMF solvent is spin-coated on a substrate and then diethyl ether is dripped while spinning, which eventually results in a transparent film that is directly indicative of the formation of adduct. The purpose of using diethyl ether is to remove only DMF to form the 1:1:1 adduct film. Thermally removal of DMSO from the adduct film controls kinetically the $\mathrm{MAPbI}_{3}$ growth. FTIR is good tool to confirm the adduct formation, where a stretching vibration of $\mathrm{S}=\mathrm{O}$ was found to shift from $1045 \mathrm{~cm}^{-1}$ for DMSO solvent to $1020 \mathrm{~cm}^{-1}$ by interacting $\mathrm{PbI}_{2}$ with $\mathrm{DMSO}$ and to $1015 \mathrm{~cm}^{-1}$ for the MAI.PbI 2 .DMSO adduct [47]. 

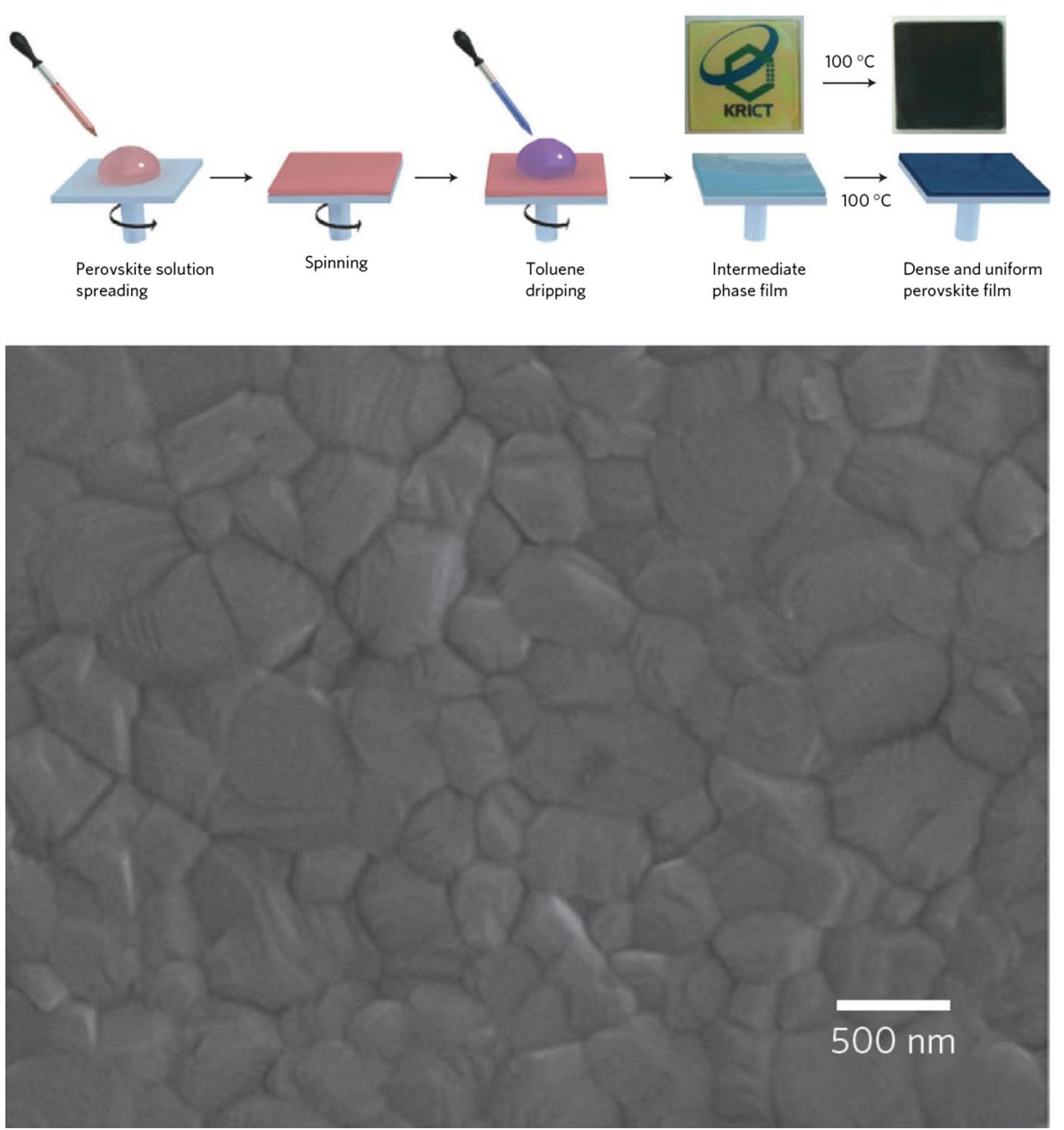

Fig. 7 (Top) a schematic illustration of solvent engineering procedure and (bottom) SEM image of the $\mathrm{MAPbl}_{3}$ produced by the solvent (toluene) engineering method. Reprinted with permission from Ref. [44]

The adduct-induced $\mathrm{MAPbI}_{3}$ layer showed flat surface with large grains. A device employing adductinduced $\mathrm{MAPbI}_{3}$ demonstrated charge carrier mobility of $3.9 \times 10^{-3} \mathrm{~cm}^{2} / \mathrm{Vs}$ (the value was measured by photoCELIV, which was lower than the value $\left(\sim 30 \mathrm{~cm}^{2} / \mathrm{Vs}\right)$ obtained by $\mathrm{THz}$ method), which was one order of magnitude higher than that $\left(3.2 \times 10^{-4} \mathrm{~cm}^{2} / \mathrm{Vs}\right)$ of $\mathrm{MAPbI}_{3}$ prepared by a simple one-step method [48]. Charge extraction characteristics was improved by the adduct method, which may be ascribed to better PL quantum yield. The best PCE of $19.7 \%$ was achieved by using the adduct method.

Since the adduct approach is generally adapted in the presence of Lewis acid and base if their frontier orbital energies are similar, this adduct approach was applied to fabrication of $\mathrm{FAPbI}_{3}$ layer. In this case, selection of Lewis base may affect the final film quality. DMSO was found to an effective Lewis base for preparing high quality $\mathrm{MAPbI}_{3}$ film. But, for the $\mathrm{FAPbI}_{3}$ case, DMSO may not be good choice because methyl group in DMSO is not matched with $\mathrm{HC}\left(\mathrm{NH}_{2}\right)_{2}$ cation in $\mathrm{FAPbI}_{3}$. Similarity of functional group is considered, where thiourea is expected to be better because of similarity of functional group between thiourea and FA. Figure 10 shows that introduction of thiourea results in highly uniform $\mathrm{FAPbI}_{3}$ film with much larger grains (from 1 to $4 \mu \mathrm{m}$ ) compared to without thiourea case (from 10 to $1 \mu \mathrm{m}$ ) [49], which is likely to correlate with stronger interaction of thiourea in adduct than DMSO, giving kinetically controlled crystal growth. XRD measurement confirmed that the X-ray crystallite size of $\mathrm{FAPbI}_{3}$ was significantly enhanced from ca. 50 to ca. $120 \mathrm{~nm}$ when $20 \%$ thiourea was added. Addition of thiourea in adduct formation showed higher PCE along with reduced I-V hysteresis compared to the $\mathrm{FAPbI}_{3}$ prepared using only DMSO. 

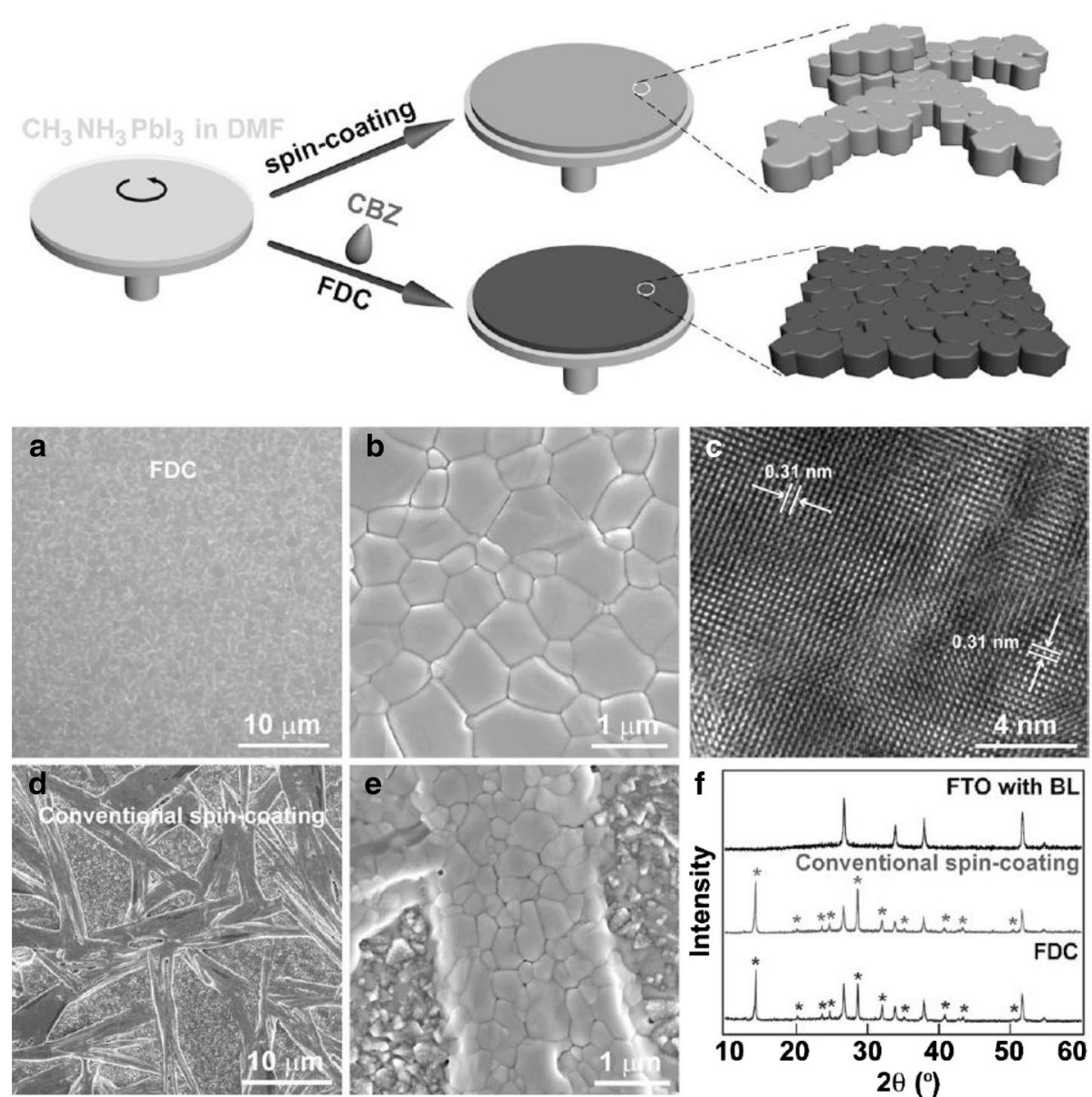

Fig. 8 (Top) schematic illustration of the FDC process and conventional spin-coating process for fabricating perovskite films. In the FDC process, a second solvent (e.g. chlorobenzene) introduced on top of the wet $\mathrm{MAPbl}_{3}$ film during the spin-coating process induces fast crystallization of uniformly sized perovskite grains. a, b Low- and high-magnification SEM plane-view images and $\mathbf{c}$ high-resolution TEM image of a MAPbl3 film prepared by FDC with the addition of chlorobenzene. $\mathbf{d}$, e Low- and high-magnification SEM images of a film prepared by conventional spin-coating without using anti-solvent. $\mathbf{f}$ XRD patterns for the films for FDC method and conventional spin-coating method. Reprinted with permission from Ref. [46]

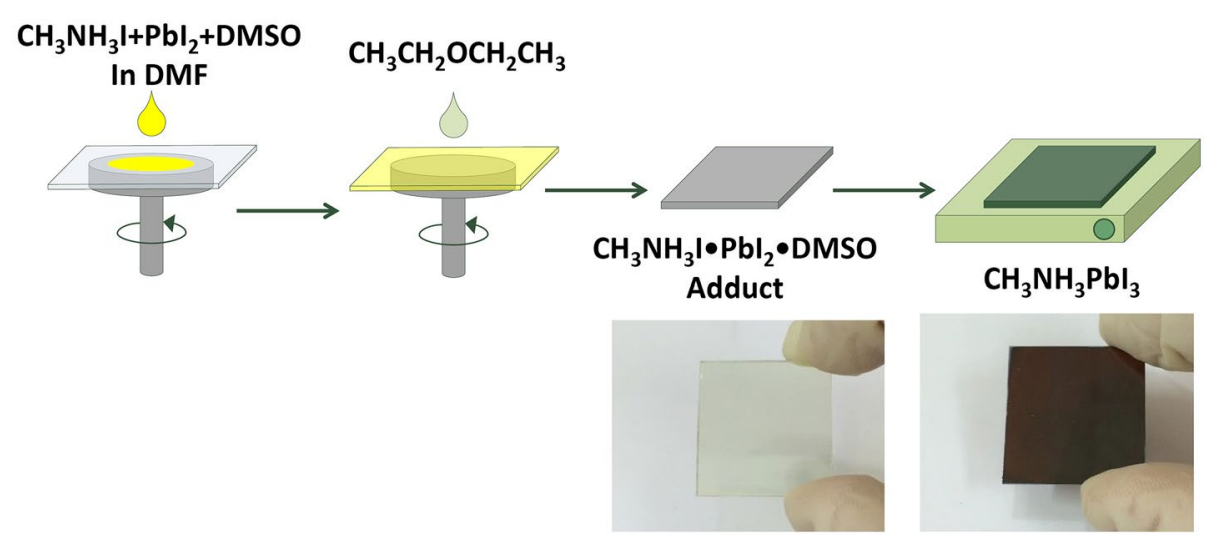

Fig. 9 A schematic procedure of the adduct method. The MAI.Pbl 2 .DMSO adduct film is transparent, which is converted to dark brown $\mathrm{MAPbl}_{3}$ upon removal of DMSO from the adduct. Reprinted with permission from Ref. [47] 


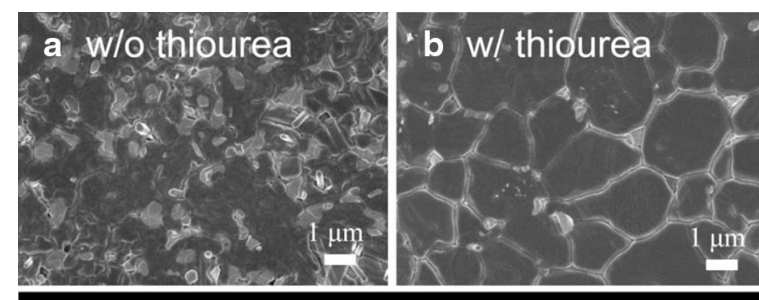

c w/o thiourea

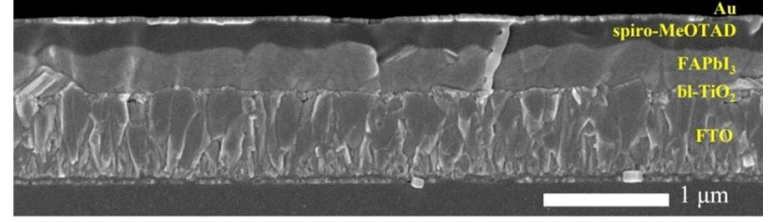

d $w /$ thiourea

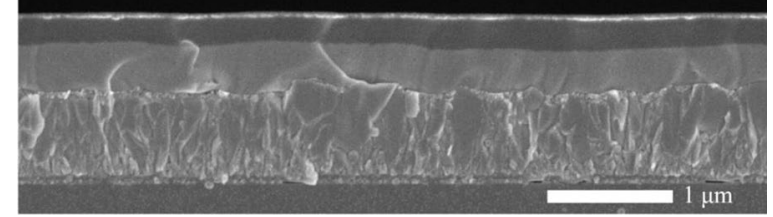

Fig. 10 Plane-view and cross-sectional SEM images of FAPbl perovskite layers formed by adduct approach a, c without thiourea (only DMSO) and b, d with thiourea (20\% thiourea and $80 \%$ DMSO). Reprinted with permission from Ref. [49]

\subsubsection{Vacuum deposition method}

Since $\mathrm{PbI}_{2}$ can be deposited by thermal evaporation [32], organo lead halide film can be prepared by vacuum deposition process. Snaith et al. reported first the vacuum-deposited $\mathrm{MAPbI}_{3}$ film and applied it to the planar heterojunction perovskite solar cell [50]. Figure 11 shows the thermal evaporation process using dual sources of $\mathrm{PbI}_{2}\left(\right.$ or $\mathrm{PbCl}_{2}$ ) and MAI and X-ray diffraction pattern of the vapor deposited $\mathrm{MAPbI}_{3}$ that is compared with the solution-processed one. In the reference 50 , the vaporprocess was argued to be better than the solution-process in planar heterojunction layout because the former produced a flat and even surface.

A sequential layer-by-layer vapor deposition was proposed similar to two-step solution process, where $\mathrm{PbCl}_{2}$ was first deposited by thermal evaporation, which was followed by vapor deposition of MAI [51]. This sequential deposition was developed because of difficulty in monitoring of MAI deposition rate in co-deposition process. Substrate was heated at temperature ranging from 65 to $85{ }^{\circ} \mathrm{C}$, in which photovoltaic performance was found to depend significantly on the substrate temperature. Higher performance was observed from the $\mathrm{MAPbI}_{3}$ layer deposited at $75{ }^{\circ} \mathrm{C}$. In Fig. 12, a schematic process for sequential vapor-deposition of perovskite film is illustrated.

Since it is difficult in adjusting stoichiometry in codeposition vacuum process, stoichiometric control is important. Inductively coupled plasma mass spectrometry (ICP-MS) was used to get the quantitative $\mathrm{I} / \mathrm{Pb}$ ratio, where omnidirectional MAI evaporation could be controlled using the chamber pressure and incorporated in the film through interaction with the unidirectionally evaporated $\mathrm{PbI}_{2}$ [52]. I/Pb was linearly proportional to chamber pressure, from which a chamber pressure of $1.23 \times 10^{-4}$ mbar and a perovskite deposition rate of $0.03 \mathrm{~nm} / \mathrm{s}$ produced stoichiometric $\mathrm{MAPbI}_{3}$. It was noted that UV-Vis spectral feature and PL peak position were almost identical regardless $\mathrm{I} / \mathrm{Pb}$ ratio, which indicates a

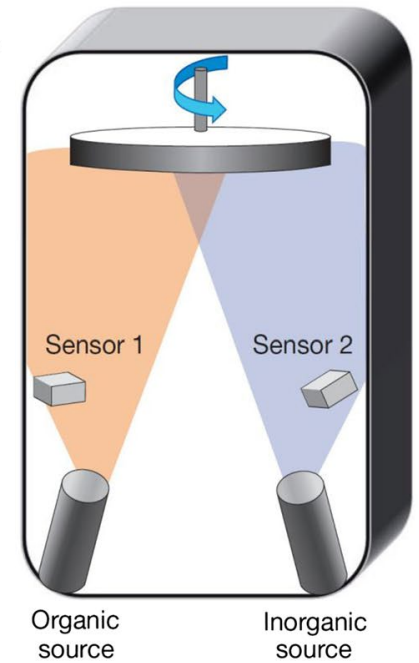

b

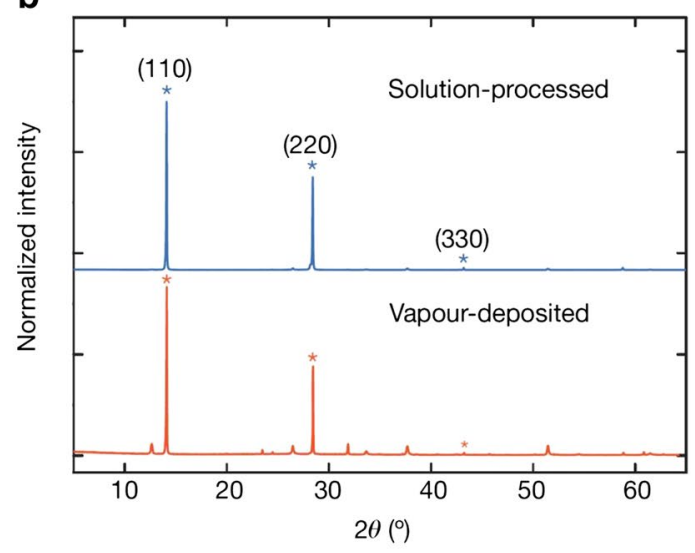

Fig. 11 a Dual-source thermal evaporation system for depositing $\mathrm{MAPbl}_{3}$ using $\mathrm{MAI}$ and $\mathrm{Pbl}_{2}\left(\mathrm{or} \mathrm{PbCl}_{2}\right)$. b X-ray diffraction patterns of a solutionprocessed $\mathrm{MAPb}_{3}$ film (b/ue) and vapor deposited one (red). Reprinted with permission from Ref. [50] 

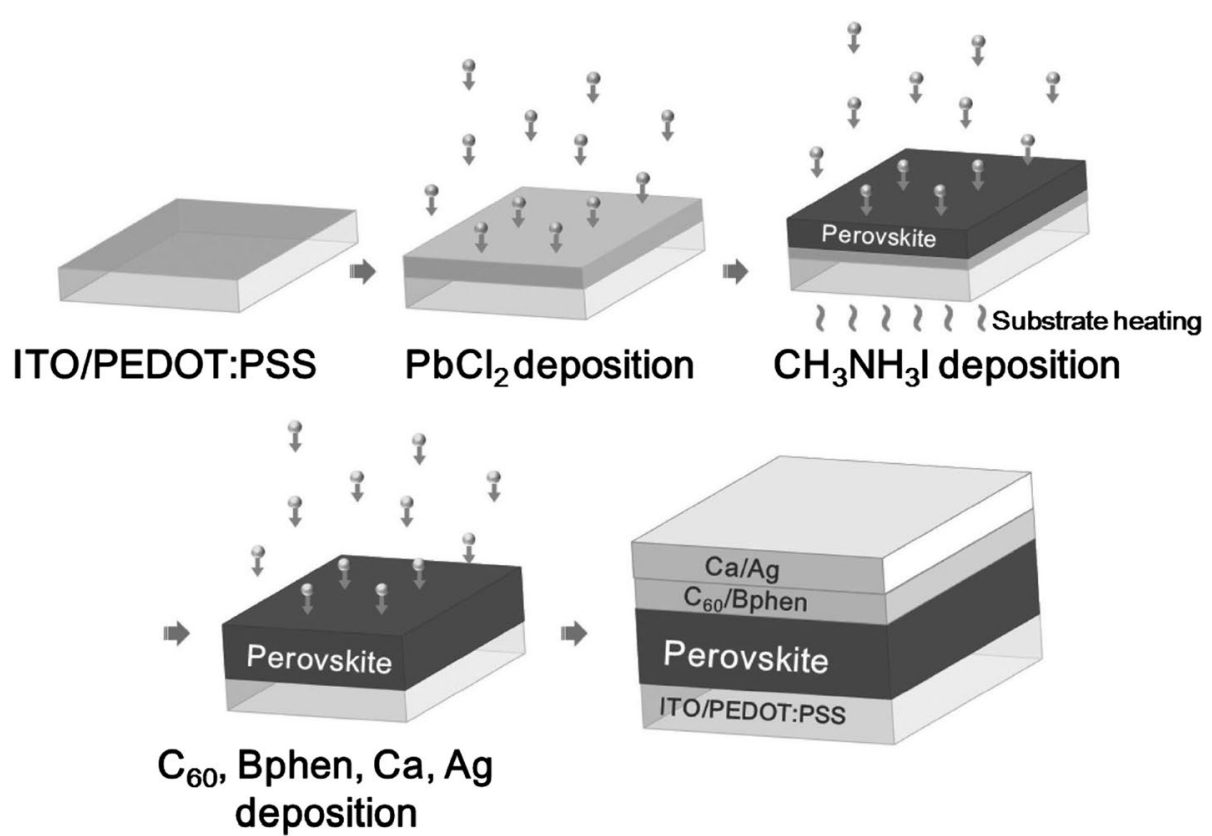

Fig. 12 Schematic illustration of perovskite solar cells fabricated by sequential layer-by-layer vacuum deposition. Reprinted with permission from Ref. [51]

that UV-Vis and PL are limited to determine the stoichiometry of $\mathrm{MAPbI}_{3}$.

\subsubsection{Combined method}

The vapor assisted solution process (VASP) was proposed to fabricate perovskite thin films, where the solution-processed $\mathrm{PbI}_{2}$ film was treated with MAI vapor [53]. This method was developed to avoid co-deposition of organic and inorganic species. VASP provided films with welldefined grain structure with grain sizes up to microscale and small surface roughness. The as-deposited $\mathrm{PbI}_{2}$ films were annealed in MAI vapor at $150{ }^{\circ} \mathrm{C}$ in $\mathrm{N}_{2}$ atmosphere for 2-4 $\mathrm{h}$ to form the uniform and large grain perovskite films. Figure 13 shows the grain growth of $\mathrm{MAPbI}_{3}$ with time, where annealing time of $30 \mathrm{~min}$ is not enough for full conversion of $\mathrm{PbI}_{2}$ to $\mathrm{MAPbI}_{3}$ but annealing for $2 \mathrm{~h}$ or longer completes the conversion process. The $\mathrm{MAPbI}_{3}$ layer thickness was found to be increased compared to the pristine $\mathrm{PbI}_{2}$ layer thickness. It should be noted that ionization energy of $\mathrm{MAPbI}_{3}$ film was varied from 5.67 to $6.4 \mathrm{eV}$ depending on preparation methods due to nonstoichiometry of final product, which was found to influence photovoltaic performance [54].

\section{Summary and outlook}

In this review, opto-electronic properties of $\mathrm{MAPbI}_{3}$, $\mathrm{FAPbI}_{3}$ and perovskites with mixed halide anions were investigated. Refractive index, dielectric constant, effective mass and charge diffusion length are important parameters for light absorbing, charge transporting and collecting. $\mathrm{MAPbI}_{3}$ is close to n-type with longer electron diffusion length but $\mathrm{FAPbI}_{3}$ is close to p-type with longer hole diffusion length, which guides design of perovskite layout. Understanding fundamentals of perovskite materials play important role in achieving high efficiency perovskite solar cell. In viewpoint of performance, high quality perovskite layer plays crucial role in overall photovoltaic parameters. Minimizing non-radiative recombination is one of methods to get high quality perovskite layer. High $\mathrm{V}_{\mathrm{oc}}$ approaching band gap energy is expected if one can reach the theoretical $V_{\text {oc }}$ deficit by engineering perovskite layer with highest internal PL quantum yield. A PCE of about $25 \%$ can be realized using $\mathrm{MAPbI}_{3}$ and/or $\mathrm{FAPbI}_{3}$ when $\mathrm{J}_{\mathrm{sc}}, \mathrm{V}_{\mathrm{oc}}$ and $\mathrm{FF}$ reach $24 \mathrm{~mA} / \mathrm{cm}^{2}$, $1.26 \mathrm{~V}\left(\mathrm{E}_{\mathrm{g}}=1.6 \mathrm{~V}\right.$ and $\mathrm{V}_{\mathrm{oc}}$ deficit $\left.=340 \mathrm{mV}\right)$ and 0.83 , respectively. 


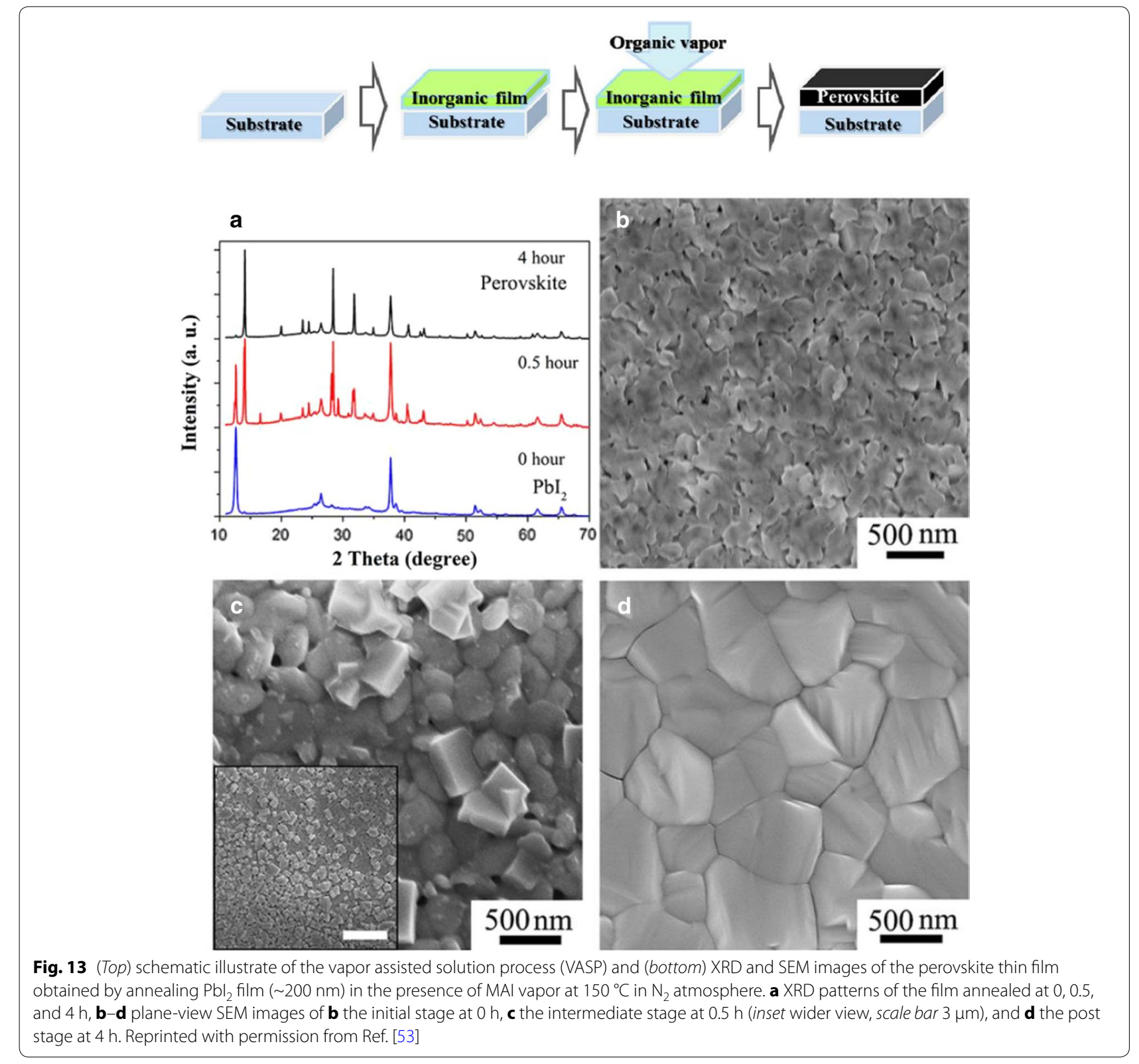

\section{Acknowledgements}

This work was supported by the National Research Foundation of Korea (NRF) Grants funded by the Ministry of Science, ICT and Future Planning (MSIP) of Korea under Contracts No. NRF-2012M3A6A7054861 (Global Frontier R\&D Program on Center for Multiscale Energy System), NRF-2015M1A2A2053004 (Climate Change Management Program), and NRF-2012M3A7B4049986 (Nano Material Technology Development Program).

\section{Competing interests}

The authors declare that they have no competing interests.

Received: 31 March 2016 Accepted: 28 April 2016

Published online: 30 June 2016

\section{References}

1. D. Weber, Z. Naturforsch. 33b, 1443-1445 (1978)

2. D. Weber, Z. Naturforsch. 33b, 862-865 (1978)

3. D.B. Mitzi, C.A. Feild, W.T.A. Harrison, A.M. Guloy, Nature 369, 467-469 (1994)

4. A. Kojima, K. Teshima, Y. Shirai, T. Miyasaka, J. Am. Chem. Soc. 131, 6050-6051 (2009)

5. J.-H. Im, C.-R. Lee, J.-W. Lee, S.-W. Park, N.-G. Park, Nanoscale 3, 4088-4093 (2011)

6. H.S. Kim, C.R. Lee, J.H. Im, K.B. Lee, T. Moehl, A. Marchioro, S.J. Moon, R. Humphry-Baker, J.H. Yum, J.E. Moser, M. Grätzel, N.G. Park, Sci. Rep. 2, 591 (2012)

7. M.M. Lee, J. Teuscher, T. Miyasaka, T.N. Murakami, H.J. Snaith, Science $\mathbf{3 3 8}$, 643-647 (2012) 
8. Q. Lin, A. Armin, R.C.R. Nagiri, P.L. Burn, P. Meredith, Nat. Photonics 9 106-112 (2014)

9. S. De Wolf, J. Holovsky, S.J. Moon, P. Löper, B. Niesen, M. Ledinsky, F.J. Haug, J.H. Yum, C. Ballif, J. Phys. Chem. Lett. 5, 1035-1039 (2014)

10. G. Xing, N. Mathews, S.S. Lim, N. Yantara, X. Liu, D. Sabba, M. Grätzel, S. Mhaisalkar, T.C. Sum, Nat. Mater. 13, 476-480 (2014)

11. C.W. Chen, S.Y. Hsiao, C.Y. Chen, H.W. Kang, Z.Y. Huang, H.W. Lin, J. Mater. Chem. A 3, 9152-9159 (2015)

12. P. Löper, M. Stuckelberger, B. Niesen, J. Werner, M. Filipič, S.J. Moon, J.H. Yum, M. Topič, S. De Wolf, C. Ballif, J. Phys. Chem. Lett. 6, 66-71 (2015)

13. J.M. Ball, S.D. Stranks, M.T. Horantner, S. Huttner, W. Zhang, E.J.W. Crossland, I. Ramirez, M. Riede, M.B. Johnston, R.H. Friend, Energy Environ. Sci. 8, 602-609 (2015)

14. X. Ziang, L. Shifeng, Q. Laixiang, P. Shuping, W. Wei, Y. Yu, Y. Li, C. Zhijian, W. Shufeng, D. Honglin, Opt. Mater. Express 5, 29-43 (2015)

15. Y. Jiang, M.A. Green, R. Sheng, A. Ho-Baillie, Sol. Energy Mater. Sol. Cells 137, 253-257 (2015)

16. C. Wehrenfennig, M. Liu, H.J. Snaith, M.B. Johnston, L.M. Herz, J. Phys. Chem. Lett. 5, 1300-1306 (2014)

17. S. Sun, T. Salim, N. Mathews, M. Duchamp, C. Boothroyd, G. Xing, T.C. Sum, Y.M. Lam, Energy Environ. Sci. 7, 399-407 (2014)

18. M.A. Green, Y. Jiang, A.M. Soufiani, A. Ho-Baillie, J. Phys. Chem. Lett. 6 4774-4785 (2015)

19. S.H. Wemple, M. DiDomenico, Phys. Rev. B 3, 1338-1351 (1971)

20. J.S. Blakemore, J. Appl. Phys. 53, R123-R181 (1982)

21. M. Samiee, S. Konduri, B. Ganapathy, R. Kottokkaran, H.A. Abbas, A. Kitahara, P. Joshi, L. Zhang, M. Noack, V. Dalal, Appl. Phys. Lett. 105, 153502 (2014)

22. D. Neamen, Semiconductor Physics and Devices, 4th ed. (McGraw-Hill, New York, 2012)

23. J. Even, L. Pedesseau, C. Katan, M. Kepenekian, J.S. Lauret, D. Sapori, E. Deleporte, J. Phys. Chem. C 119, 10161-10177 (2015)

24. G. Giorgi, J.I. Fujisawa, H. Segawa, K. Yamashita, J. Phys. Chem. Lett. 4 4213-4216 (2013)

25. G. Xing, N. Mathews, S. Sun, S.S. Lim, Y.M. Lam, M. Grätzel, S. Mhaisalkar, T.C. Sum, Science 342, 344-347 (2013)

26. G.E. Eperon et al., Energy Environ. Sci. 7, 982-988 (2014)

27. C.C. Stoumpos et al., Inorg. Chem. 52, 9019-9038 (2013)

28. K. Galkowski, A. Mitioglu, A. Miyata, P. Plochocka, O. Portugall, G.E. Eperon, J.T.W. Wang, T. Stergiopoulos, S.D. Stranks, H.J. Snaith, R.J. Nichola, Energy Environ. Sci. (2016). doi:10.1039/c5ee03435c

29. W. Rehman, R.L. Milot, G.E. Eperon, C. Wehrenfennig, J.L. Boland, H.J. Snaith, M.B. Johnston, L.M. Herz, Adv. Mater. 27, 7938-7944 (2015)

30. C. Wehrenfennig, M. Liu, H.J. Snaith, M.B. Johnston, L.M. Herz, Energy Environ. Sci. 7, 2269 (2014)
31. C.M. Sutter-Fella, Y. Li, M. Amani, J.W. Ager, F.M. Toma, E. Yablonovitch, I.D. Sharp, A. Javey, Nano Lett. 16, 800-806 (2016)

32. K. Liang, D.B. Mitzi, M.T. Prikas, Chem. Mater. 10, 403-411 (1998)

33. J. Burschka, N. Pellet, S.J. Moon, R. Humphry-Baker, P. Gao, M.K. Nazeeruddin, M. Grätzel, Nature 499, 316-319 (2013)

34. J.H. Im, I.H. Jang, N. Pellet, M. Grätzel, N.G. Park, Nat. Nanotechnol. 9 927-932 (2014)

35. N. Ahn, S.M. Kang, J.W. Lee, M. Choi, N.G. Park, J. Mater. Chem. A 3 19901-19906 (2015)

36. S. Mastroianni, F.D. Heinz, J.H. Im, W. Veurman, M. Padilla, M.C. Schubert, U. Würfel, M. Grätzel, N.G. Park, A. Hinsch, Nanoscale 7, 19653-19662 (2015)

37. H.S. Ko, J.W. Lee, N.G. Park, J. Mater. Chem. A 3, 8808-8815 (2015)

38. Y. Xu, L. Zhu, J. Shi, X. Xu, J. Xiao, J. Dong, H. Wu, Y. Luo, D. Li, Q. Meng, ChemPhysChem 17, 112-118 (2016)

39. M.I. El-Henawey, R.S. Gebhardt, M.M. El-Tonsy, S. Chaudhary, J. Mater. Chem. A 4, 1947-1952 (2016)

40. B. Yang, O. Dyck, J. Poplawsky, J. Keum, S. Das, A. Puretzky, T. Aytug, P.C. Joshi, C.M. Rouleau, G. Duscher, D.B. Geohegan, K. Xiao, Angew. Chem. Int. Ed. 54, 14862-14865 (2015)

41. J.H. Huang, K.J. Jiang, X.P. Cui, Q.Q. Zhang, M. Gao, M.J. Su, L.M. Yang, Y. Song, Sci. Rep. 5, 15889 (2015)

42. W.S. Yang, J.H. Noh, N.J. Jeon, Y.C. Kim, S. Ryu, J. Seo, S.I. Seok, Science $\mathbf{3 4 8}$ 1234-1237 (2015)

43. J.H. Im, H.S. Kim, N.G. Park, APL Mater. 2, 081510 (2014)

44. N.J. Jeon, J.H. Noh, Y.C. Kim, W.S. Yang, S. Ryu, S.I. Seok, Nat. Mater. 13, 897-903 (2014)

45. N.J. Jeon, J.H. Noh, W.S. Yang, Y.C. Kim, S. Ryu, J. Seo, S.I. Seok, Nature 517, 476-480 (2015)

46. M. Xiao, F. Huang, W. Huang, Y. Dkhissi, Y. Zhu, J. Etheridge, A. Gray-Weale, U. Bach, Y.B. Cheng, L. Spiccia, Angew. Chem. Int. Ed. 53, 9898-9903 (2014)

47. N. Ahn, D.Y. Son, I.H. Jang, S.M. Kang, M. Choi, N.G. Park, J. Am. Chem. Soc. 137, 8696-8699 (2015)

48. Y. Chen, J. Peng, D. Su, X. Chen, Z. Liang, A.C.S. Appl, Mater. Interfaces 7, 4471-4475 (2015)

49. J.W. Lee, H.S. Kim, N.G. Park, Acc. Chem. Res. 49, 311-319 (2016)

50. M. Liu, M.B. Johnston, H.J. Snaith, Nature 501, 395-398 (2013)

51. C.W. Chen, H.W. Kang, S.Y. Hsiao, P.F. Yang, K.M. Chiang, H.W. Lin, Adv. Mater. 26, 6647-6652 (2014)

52. J. Teuscher, A. Ulianov, O. Mintener, M. Grätzel, N T|treault. ChemSusChem 8, 3847-3852 (2015)

53. Q. Chen, H. Zhou, Z. Hong, S. Luo, H.S. Duan, H.H. Wang, Y. Liu, G. Li, Y. Yang, J. Am. Chem. Soc. 136, 622-625 (2014)

54. J. Emara, T. Schnier, N. Pourdavoud, T. Riedl, K. Meerholz, S. Olthof, Adv. Mater. 28, 553-559 (2016)

\section{Submit your manuscript to a SpringerOpen ${ }^{\circ}$ journal and benefit from:}

- Convenient online submission

- Rigorous peer review

- Immediate publication on acceptance

- Open access: articles freely available online

- High visibility within the field

- Retaining the copyright to your article

Submit your next manuscript at springeropen.com 